\title{
Knowledge, Attitude and Practice of Medical Students towards Low Blood Pressure Syndrome
}

\author{
Pooja Deepak, Khalid Imran, Aqsa Saleem, Naresh Kumar Seetlani, Daniyal Mirza, \\ Arun Kumar Bhojwani, Jaish Kumar
}

\section{ABSTRACT}

INTRODUCTION: Normal blood pressure has a certain normal range and therefore it is common to see people having blood pressure towards lower range but considering it as "low blood pressure". Among these majority of the people including medical students consider "low blood pressure" as a disease which once diagnosed, needs to be treated.

OBJECTIVE: The objective of this study is to evaluate the knowledge and attitude of medical students towards low blood pressure.

METHODOLOGY: This cross-sectional study was conducted by recruiting medical students (MBBS) of Dow Medical College, Civil Hospital Karachi during October 2016 to February 2017. A total of 306 students from first year to final year were approached through after an informed consent and questionnaire regarding the symptoms of low blood pressure were noted. The students were divided equally into pre-clinical ( $1^{\text {st }}$ and $2^{\text {nd }}$ year students) and clinical $\left(3^{\text {rd }}, 4^{\text {th }}\right.$ and $5^{\text {th }}$ year) groups to assess difference in between their knowledge based on their clinical exposure. Every participant underwent blood pressure measurement regardless of the symptoms. Results were compared and analyzed using SPSS software version 16.0 .

RESULTS: 171 ( $n=100$ from clinical and $n=71$ from pre-clinical group) students out of a total of 306 participants do not consider low blood pressure a disease. They also believe that low blood pressure among healthy people neither presents with any symptoms nor requires any treatment.

CONCLUSION: It is concluded by our study that most of the students enrolled in a medical college believe that low blood pressure is a normal entity for a person which doesn't require any intervention.

KEYWORDS: low blood pressure, constitutional hypotension, medical students

This article may be cited as: Deepak P, Imran K, Saleem A, Seetlani NK, Mirza D, Bhojwani AK, Kumar J. Knowledge, Attitude and Practice of Medical Students towards Low Blood Pressure Syndrome. J Liaquat Uni Med Health Sci. 2017;16(03):181-5. doi: 10.22442/jlumhs.171630530

\section{INTRODUCTION}

Blood pressure is the force by which blood pushes against the walls of arteries as it gets pumped by the heart. It is measured as "systolic" (the pressure with which heart pumps the blood into the circulation) and "diastolic" (in which heart relaxes between the beats) pressures. Optimal blood pressure in adults should be less than $120 / 80 \mathrm{~mm} \mathrm{Hg}$ (where systolic is 120 and diastolic is 80$)^{1}$. But blood pressure is a very variable vital, it can either go below or above the optimal limits. It changes as person sleeps and wakes up, rises as a person gets excited, nervous or active and lowers as a person gets depressed or anxious ${ }^{2}$. A blood pressure greater than $120 / 80$ is known as "high blood pressure or Hypertension."According to the current classification based on the Seventh Report of the Joint National Committee on Prevention, Detection, Evaluation, and Treatment of High Blood Pressure (JNC 7), hypertension is classified as Pre-hypertension (BP $\geq 120 / 80$ $\mathrm{mm} \mathrm{Hg}$ ), Hypertension stage 1 (BP > 140/90 mm Hg) and Hypertension stage $2(\mathrm{BP}>160 / 100 \mathrm{~mm} \mathrm{Hg})^{3}$. While a blood pressure below the cut off values is referred to as "low blood pressure or Hypotension." These cutoff values differ in males and females. Males having a systolic blood pressure under $110 \mathrm{~mm} \mathrm{Hg}$ and females having under $100 \mathrm{~mm} \mathrm{Hg}$ with diastolic being under $60 \mathrm{~mm} \mathrm{Hg}$ are considered hypotensive ${ }^{4}$,

However low blood pressure to some extent is considered better than high blood pressure. It is seen that a blood pressure below normal without any evidence of underlying pathology is beneficial. It increases the life expectancy of a person and makes him more physically vigor and potent ${ }^{5}$. b On the other hand, there are many complications associated with high blood pressure like cerebro vascular, cardiovascular and renal pathologies ending up with various disturbing symptoms in a person's life ${ }^{6}$. Nevertheless, there are some symptoms caused by decrease in 
blood pressure as well which includes tiredness, dizziness, lack of concentration, fainting, blackouts, sleep disturbances, palpitation, sweating etc ${ }^{4}$. but such symptoms are more commonly seen either in certain medical illnesses causing hypotension like coronary thrombosis, shock, vasovagal attacks, drop attacks in the elderly, Addison disease, cachexia, Tuberculosis, Parkinson's disease, Diabetes, anorexia nervosa, ${ }^{4}$ or due to intake of many drugs like beta blockers, ACE inhibitors, calcium channel blockers and thiazides ${ }^{7}$ or due to certain food items like garlic, ginger, celery, green oat, tea, carrot, radish, tomato, chocolate, cocoa butter etc ${ }^{8}$, all of these possibilities should be kept in mind when a person presents with low blood pressure. Even though there are so many people who tend to have low blood pressure all the times but do not experience any symptoms of hypotension which is considered normal and therefore need no treatment for it ${ }^{6}$. It is necessary to evaluate whether low blood pressure in an individual should be considered a disease or not and more importantly should it be treated or not. Many of the general practitioners treat low blood pressure unnecessarily with intravenous infusions and vitamin injections and with no doubt this practice has become very common in our society may be because of lack of knowledge or their own negligence and has resulted in an increase incidence of hepatitis $B$ and $C$ due to unsafe needle use ${ }^{9}$.

Much work has been done about hypertension but data on hypotension, its symptoms and treatment is very scarce in literature which is the main reason for dearth of knowledge even among medical practitioners and students and is very unfortunate as many of the people get mistreated because of this negligence. Hence, the rationale of our study focused on medical students is to assess their knowledge and belief about low blood pressure that whether it's a disease which causes symptoms and requires proper treatment or it's just a normal entity without any need of intervention which holds a great importance.

\section{Objective}

The objective of our study is to assess the knowledge and insight of medical students belonging to pre-clinical and clinical academic groups of study towards low blood pressure syndrome, its associated symptoms and interventions.

\section{METHODOLOGY}

After approval from the ethical review board this cross -sectional study was carried out at Dow Medical College, Civil Hospital Karachi from October 2016 to February 2017. Sample size was calculated using open epi website ${ }^{10}$ using an anticipated frequency of $73 \% 9$. A total of 306 medical students of $1^{\text {st }}$ year to final year were selected using convenient sampling technique. All those selected were categorized into two groups; pre-clinical students $\left(1^{\text {st }}\right.$ and $2^{\text {nd }}$ year) and clinical students $\left(3^{\text {rd }}\right.$ to $5^{\text {th }}$ year), to assess whether clinical training of the students influenced knowledge of the students towards low blood pressure. A questionnaire in English language designed by principal investigator was used as a tool to collect relevant information, these includes personal bio data, questions regarding low blood pressure, its symptoms and possible intervention commonly sought for as remedy. After explaining nature of the study and reassurance to the participants about the confidentiality of the personal data, consent was taken. Questionnaire was given to the participant to be filled in while blood pressure was recorded by the researcher themselves using mercury sphygmomanometer. Blood pressure was told to each participant after measuring it. Data entered and analyzed using Statistical Package for the Social Sciences (SPSS) version 16.0. It is presented as percent and Chi square used to identify the differences between both groups.

\section{RESULTS}

Among 306 students with equal participation of pre-clinical and clinical ( $n=153$ each) 215 were females and 91 were males. A total of 171 students $(55.9 \%) ; 71$ students $(46.4 \%)$ from pre-clinical and 100 students $(65.3 \%)$ from clinical group, do not consider low blood pressure a disease while the remaining 135 students (44.1\%); 82 students (53.5\%) from pre-clinical and 53 students (34.6\%) from clinical, consider low blood pressure a disease (Figure 1). A $\mathrm{p}$-value of 0.001 was obtained which was statistically significant (Table 1).Among 135 students (44.1\%) who affirmed that low blood pressure is a disease and does present with symptoms, 110 students (35.9\%) consider fatigue to be the most common presenting symptom whereas dizziness appeared to be the second most common symptom, with a p-value of 0.213 which was not statistically significant. Assessing the blood pressure of students themselves, a total of 33 participants had a systolic blood pressure below normal range i.e.7 males $(2.28 \%)$ of both the groups having $<110 \mathrm{~mm} \mathrm{Hg}(p$-value $=0.113)$ and 26 females $(8.49 \%)$ had blood pressure $<100 \mathrm{~mm} \mathrm{Hg}$ ( $p$-value= 0.744 ) while a total of 273 participants had blood pressure in normal range; 82 males $(26.7 \%)$ and 191 females $(62.4 \%)$ of both the groups. On feeling any of the symptoms by participants themselves, a total of 197 students $(64.4 \%)$ admitted that they felt symptoms like fatigue, dizziness, headache etc. over a period of past two weeks which also had a non-significant 
Pooja Deepak, Khalid Imran, Aqsa Saleem, Naresh Kumar Seetlani, Daniyal Mirza, Arun Kumar Bhojwani, Jaish Kumar

TABLE I: PERCEPTION OF STUDENTS TOWARDS LOW BLOOD PRESSURE SYNDROME ACCORDING TO THEIR ACADEMIC GROUPS

\begin{tabular}{|c|c|c|c|c|c|c|c|c|}
\hline \multirow{3}{*}{\multicolumn{2}{|c|}{ Variable }} & \multicolumn{4}{|c|}{ Academic groups } & \multicolumn{2}{|c|}{ Total students (306) } & \multirow{3}{*}{ P-value } \\
\hline & & \multicolumn{2}{|c|}{ Pre-clinical (153) } & \multicolumn{2}{|c|}{ Clinical (153) } & \multirow[b]{2}{*}{$\mathrm{N}$} & \multirow[b]{2}{*}{$\%$} & \\
\hline & & $\mathrm{N}$ & $\%$ & $\mathrm{~N}$ & $\%$ & & & \\
\hline \multirow{2}{*}{ Gender } & Male & 51 & 33.3 & 40 & 26.1 & 91 & 29.8 & \multirow{2}{*}{1.169} \\
\hline & Female & 102 & 66.6 & 113 & 73.8 & 215 & 70.2 & \\
\hline \multirow{2}{*}{$\begin{array}{l}\text { Consider low BP a } \\
\text { disease }\end{array}$} & Yes & 82 & 53.5 & 53 & 34.6 & 135 & 44.1 & \multirow{2}{*}{0.001} \\
\hline & No & 71 & 46.4 & 100 & 65.3 & 171 & 55.9 & \\
\hline \multirow{2}{*}{$\begin{array}{l}\text { Blood pressure of } \\
\text { Participants below } \\
\text { normal range }\end{array}$} & Male & 6 & 3.9 & 1 & 0.65 & 7 & 2.28 & 0.113 \\
\hline & Female & 15 & 9.80 & 11 & 7.18 & 26 & 8.49 & 0.744 \\
\hline \multirow{5}{*}{$\begin{array}{l}\text { Symptoms occurring } \\
\text { with low BP }\end{array}$} & Fatigue & 62 & 40.5 & 48 & 31.4 & 110 & 35.9 & \multirow{5}{*}{0.213} \\
\hline & Dizziness & 09 & 5.80 & 03 & 1.9 & 12 & 3.9 & \\
\hline & Headache & 06 & 3.90 & 02 & 1.2 & 08 & 2.6 & \\
\hline & Depression & 03 & 1.90 & 00 & 00 & 03 & 0.9 & \\
\hline & Sweating & 02 & 1.30 & 00 & 00 & 02 & 0.6 & \\
\hline \multirow{2}{*}{$\begin{array}{l}\text { Symptoms felt by } \\
\text { themselves }\end{array}$} & Yes & 95 & 62.1 & 102 & 66.7 & 197 & 64.4 & \multirow{2}{*}{0.403} \\
\hline & No & 58 & 37.9 & 51 & 33.3 & 109 & 35.6 & \\
\hline \multirow{2}{*}{$\begin{array}{l}\text { Low BP require } \\
\text { treatment }\end{array}$} & Yes & 76 & 49.7 & 50 & 32.7 & 126 & 41.2 & \multirow{2}{*}{0.003} \\
\hline & No & 77 & 50.3 & 103 & 67.3 & 180 & 58.8 & \\
\hline \multirow{5}{*}{ Treatment for low BP } & Table salt & 70 & 45.7 & 45 & 29.4 & 115 & 37.5 & \multirow{5}{*}{0.892} \\
\hline & Table sugar & 02 & 1.3 & 02 & 1.3 & 04 & 1.30 & \\
\hline & Fruit juice & 02 & 1.3 & 02 & 1.3 & 04 & 1.30 & \\
\hline & IV dextrose & 01 & 0.6 & 00 & 00 & 01 & 0.3 & \\
\hline & IV saline & 01 & 0.6 & 01 & 0.6 & 02 & 0.6 & \\
\hline
\end{tabular}

p-value of 0.403. A total of 180 students $(58.8 \%) ; 77$ students $(50.3 \%)$ from pre-clinical and $103(67.3 \%)$ from clinical group stated that low blood pressure should not be treated as long as it is asymptomatic while the remaining 126 students $(41.2 \%) ; 76$ students $(49.7 \%)$ from pre-clinical and 50 students (32.7\%) from clinical group believed that low blood pressure even without any symptoms should be managed with certain interventions. This gave a significant $p$-value of 0.003 ; the administration of table salt being the most common modality having a p-value of 0.892 which was not significant.

FIGURE I: PIE CHART SHOWING THE RESPONSE OF MEDICAL STUDENTS TOWARDS LOW BLOOD PRESSURE SYNDROME

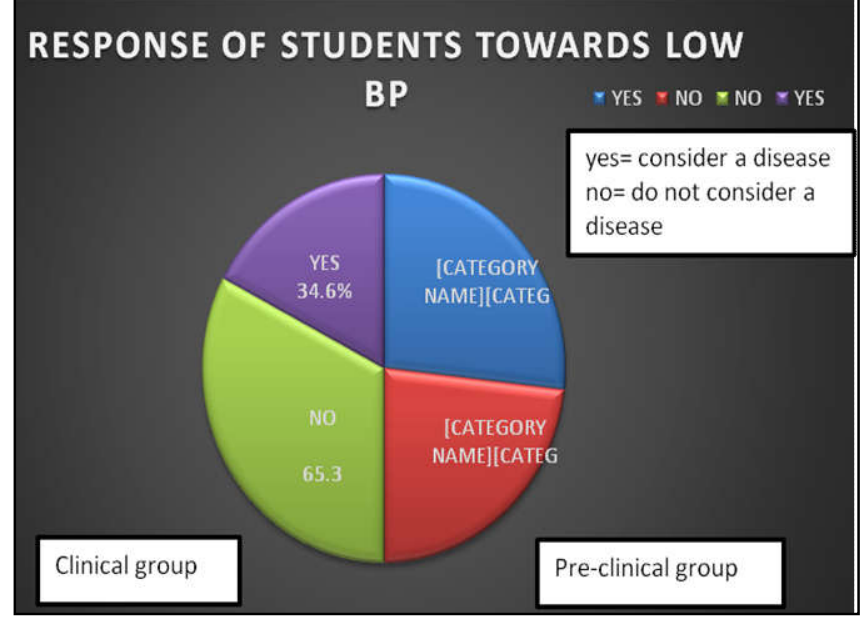




\section{DISCUSSION}

Low blood pressure has not been a subject of interest to many medical students or practitioners, as not much work has been done on this topic and no detailed discussions are available in medical literature; yet it is a very important clinical issue faced by many medical practitioners. For a very long time, low blood pressure has remained an unsolved mystery even among medical personnel and it is not certain whether to consider it a normal phenomenon or a disease that requires treatment. In our study, we have assessed the knowledge of medical students towards low blood pressure syndrome, its associated symptoms and interventions. It has been found in current study that $55.9 \%$ medical students; majority from clinical group, do not consider low blood pressure a disease (0.001) but a normal entity. This significant difference between perception of pre-clinical and clinical medical students may be attributed to sound clinical training of the clinical students. Our result coincides with the study of John Pemberton in which the United States, British and Australian authorities postulated that asymptomatic low blood pressure is not a disease, in fact a person with blood pressure below normal ranges has a greater life expectancy than in the normal range ${ }^{4}$. While the German, French and Italy considered blood pressure below normal range as a disease ${ }^{4}$. In fact, according to a local study, $73 \%$ of the Pakistani population considers low blood pressure a disease ${ }^{9}$ presenting with corporal symptoms which is contradictory to our results. This huge variation in the theories suggests that consideration of low blood pressure as a disease or not highly depends on different ethnicities and varies per their norms and believes. In current study, the most common symptom attributed to low blood pressure was fatigue $(35.9 \%)$, a finding in agreement with the study of Wessely $\mathrm{S}$. who also stated that systemic hypotension is associated with persistent tiredness ${ }^{11}$. Similar results are reported by Lucas at al ${ }^{12}$ which stated that low blood pressure tends to cause chronic fatigue but more commonly in women than their counterparts. The presence of fatigue as the most common symptom might be due to that whenever blood pressure drops below normal, blood gets pooled in the dependent vessels and oxygen supply to the tissues decreases due to which cells undergo anaerobic oxygenation. This accumulates many of the unwanted acidotic metabolites which is the reason of producing a feeling of tiredness and fatigue ${ }^{13}$.

Considering the symptoms felt by all the participants $(n=306), 197$ students admitted that when they did come across few physical symptoms; they cross-cheeked association of their symptoms with their blood pressure. Among these only 33 participants found association of their symptoms with low blood pressure while 273 participants confessed that their blood pressure was within normal limit yet they experienced symptoms. Thus, it can be assumed that low blood pressure is not always a cause of such corporal symptoms but a person with normal blood pressure can experience such symptoms and a person with a low blood pressure can remain without experiencing any symptoms. According to our study, a total of 180 students out of 306 from both the groups believed that low blood pressure doesn't need to be treated if it is asymptomatic. The rationale behind this belief might be that most of the healthy people usually have blood pressure below normal range which does not bother them or has any detrimental effects on their lives. This finding coincides with the authorities of the US, Australia, Canada and Britain in Wessely S. and in John Pemberton studies who also consider that constitutional hypotension doesn't need any intervention $^{4,11}$. In contradictory, the remaining 126 students believe that even asymptomatic low blood pressure should be treated with table salt being the most common modality used. This finding is strongly supported by the study done at Aga Khan University Hospital on general population of Karachi who also postulated the use of salt to manage low blood pressure $^{9}$. Besides this, Germany, France and Italy also commonly treat asymptomatic low blood pressure using various modalities like anti-hypotensive drugs, ergotamine, amphetamines or ephedrine ${ }^{4}$. All these drugs have pressor response i.e. they stimulate the sympathetic nervous system thus play a role in optimizing or increasing the blood pressure ${ }^{14}$. According to Barnett and Wagner ${ }^{15}$ classification, phenylephrine and nor-adrenaline directly act on vessels and constrict them thus increase the blood pressure while amphetamines and ephedrine increase the blood pressure indirectly by inhibiting the destruction of nor-adrenaline at the sympathetic nerve endings.

\section{CONCLUSION}

We concluded that $55.9 \%$ medical students, mostly from clinical group do not consider asymptomatic low blood pressure a disease and believe that it does not need any treatment.

\section{LIMITATIONS}

This cross-sectional study was conducted in a single institute of the city with small sample size and convenience sampling. It was done on a small sample size compared to the total number of students enrolled in the college and were selected via convenience sampling. These limitations did not determine the cross effective associations, that's why a more 
extended study on a larger scale should be done for a better scrutiny and more precision of the findings.

\section{REFRENCES}

1. National Heart, Lung and Blood Institute. What is hypotension? Available from: https:// www.nhlbi.nih.gov/health/health-topics/topics/hyp

2. Hildrum B, Mykletun A, Stordal E, et.al. Association of low blood pressure with anxiety and depression: the Nord Trondelag health study. J Epidemiol Community Health. 2007; 61(1):53-8.

3. Giles TD, Berk BC, Black HR, Cohn JN, Kostis $\mathrm{JB}$, Izzo Jr JL, et al. Expanding the Definition and Classification of Hypertension. J Clin Hypertens. 2005; 7(9):505-12.

4. Pemberton J. Does constitutional hypotension exist? BMJ. 1989; 298(6674):660-2.

5. Friedlander A. Clinical types of Hypotension. JAMA. 1924; 83(3):167-171.

6. American Heart association. Low Blood Pressure. [online] 2005 [ cited 2005 Oct 25] Available from: URL: http://www.americanheart.org/ presenter.jhtml?identifier $=4643$

7. Law MR, Morris JK, Wald NJ. Use of blood pressure lowering drugs in the prevention of cardiovascular disease: meta-analysis of 147 randomized trials in the context of expectations from prospective epidemiological studies. BMJ. 2009; 338:b1665.
8. Tabassum N, Ahmad F. Role of natural herbs in the treatment of hypertension. Pharmacogn Rev. 2011 Jan-Jun; 5(9):30-40.

9. Qidwai W, Tara Chand B. Low blood pressure syndrome: A myth or reality? Results of a patient's survey at a teaching hospital in Karachi. Pak $\mathrm{J}$ Med Sci, October - December 2006; 22(4): 373-8.

10. Dean AG, Sullivan KM, Soe MM. OpenEpi: Open Source Epidemiologic Statistics for Public Health, Version 3.01 Update 2013/04/06. Available from: http://www.openepi.com.

11. Wessely S, Nickson J, Cox B. Symptoms of low blood pressure: a population study. BMJ. 1990 Aug 18;301(6748):362-365.

12. Lucas KE, Rowe PC, Coresh J, Klag MJ, Meoni LA, Ford DE. Prospective association between hypotension and idiopathic chronic fatigue. J Hypertens. 2004; 22(4):691-95.

13. Simpson LO. Symptoms of low blood pressure. BMJ. 1990; 301(6755): 815-6.

14. Davies B, Bannister R, Sever P. Pressor amines and Monoamine-Oxidase Inhibitors for Treatment of Postural Hypotension in Autonomic Failure: Limitations and Hazards. Lancet (London England). 1978; 311(8057):172-5.

15. Parks VJ, Sandison AG, Skinner SL, Whelan RF. Sympathomimetic drugs in orthostatic hypotension. The Lancet. 1961; 277(7187):1133-6.

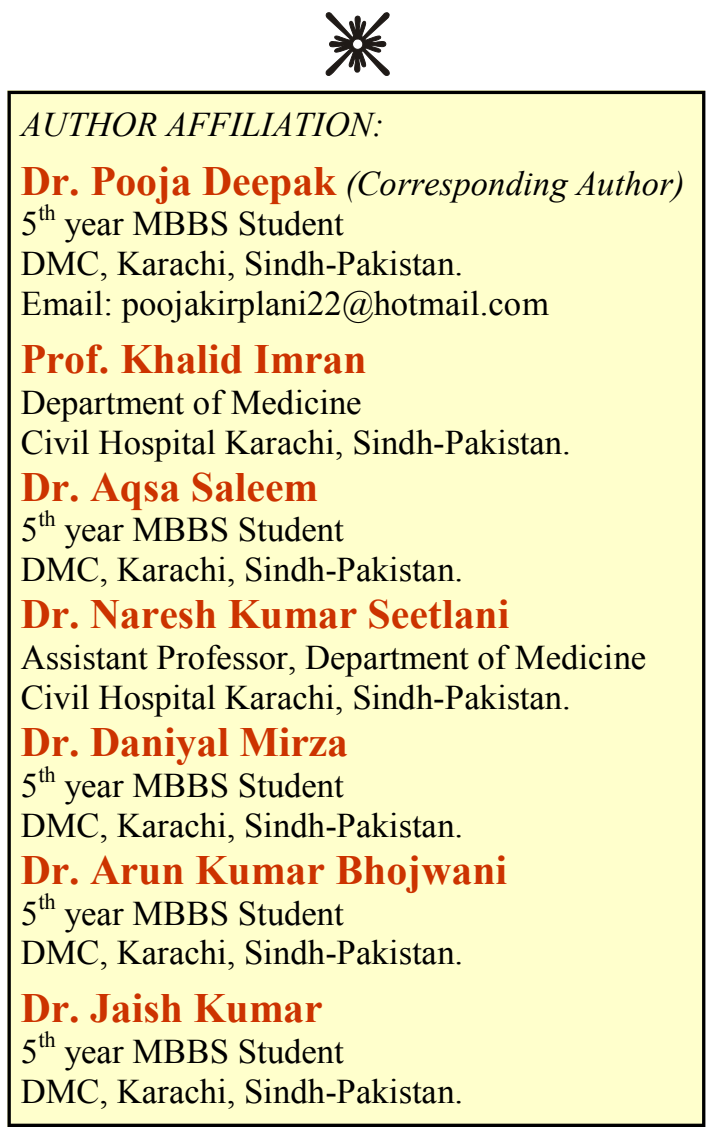

